\title{
Condition inspections of residential property - a procedural framework
}

\author{
Mike Hoxley
}

Department of Built Environment, Anglia Polytechnic University, Chelmsford, UK.

\begin{abstract}
Presents a procedural framework for the inspection of domestic property. A mechanistic task such as sketching the site plan and roof plan is advocated in order to achieve focus, familiarity and freedom to undertake the inspection alone. An inspection of the exterior followed by the interior is recommended and a "top-down" procedure is suggested. The type of information to record and how to record it are both discussed and the existing and forthcoming benchmark standards of SAVA are referred to.
\end{abstract}

Keywords: Residential surveys, inspections, procedural framework.

\section{Introduction - the 3Fs.}

This paper is principally concerned with the beginning of a survey inspection, that is not with what precedes the inspection in the office but with how the surveyor should commence and plan what is undoubtedly the most important and demanding of the activities involved with a survey - the actual inspection. During the early stages of an inspection it is essential to clear the mind so that the task in hand can be carried out with the full level of skill demanded by the client (and perhaps more importantly by the courts). It is likely that the surveyor will have arrived on site thinking about the previous job he or she has been undertaking and he or she needs to forget about this and focus upon the property to be inspected. There is no doubt that this is easier with an empty property than with one which is occupied. Where the existing owner or occupier is present during the inspection there is always the danger that the surveyor could be distracted by their presence. It is important for the surveyor to be single-minded in carrying out the inspection and to "lose" the occupier as soon as possible after arriving on site. 
The other essential element of the preliminary part of a survey is to quickly become familiar with the property - with the extent of the buildings and site. A good method of achieving all of these objectives (the "3 Fs" - focus, familiarity and freedom) is to carry out a measured survey of the plot and building's footprint and on the plan to plot a sketch roof plan. This is all essential information that needs to be recorded during the inspection and by the time that this fairly mechanistic and straightforward task has been completed the occupier will usually have lost interest and returned to the interior of the building, the surveyor will be aware of the extent of the site and buildings, and hopefully be concentrating fully on the survey.

\section{Sequence of inspection}

Authorities differ upon the question of whether it is better to commence the full inspection internally or externally. Many suggest that it is better to inspect internally initially as this will cause the least inconvenience to the occupier (Melville et al, 1992), while others seem to suggest that commencing with an external inspection follows more logically the order in which it is usual to report (Hollis, 2000). The writer favours the latter approach as he is not particularly concerned with the sensibilities of the occupier and if anything is missed during the initial inspection of the exterior it is an easy task to reinspect part of the exterior again. It may not be as easy to re-inspect the interior again if any problem is suggested by the external inspection. Say, for example, the inspection of the roof-space reveals rain penetration around a chimney stack. If no defect had been identified during the initial external inspection of the stack, it is an easy matter to re-inspect the chimney stack flashings for any sign of a problem. However, let us now assume that the inspection had been carried out in the reverse order and that no defect had been noticed in the roof-space. If then a problem with the flashing is identified by the external inspection it may be more difficult to gain access to the roofspace for the second time (perhaps involving unscrewing a trap door, placing dust sheets and erecting a ladder). In many respects the order of inspection is a matter of the personal preference of the surveyor but what is most important is that the inspection is carried out in a logical sequence with which 
the surveyor is familiar and that the surveyor is not afraid to retrace his footsteps in order to follow a trail of evidence.

To summarise the discussion above, the writer's preferred sequence for the inspection of the property is as follows:

- Measured survey of the plot and footprint of the building;

- Inspection of the exterior;

- Inspection of the interior.

The exterior inspection will now be considered.

\section{Inspecting the exterior}

It is best to inspect each element of construction in turn as this mirrors how the report will be structured. However this is not always practical particularly where the property being inspected is in the centre of a terrace. In such a situation it is necessary to inspect each elevation in turn and indeed this is the method of recording information followed by many surveyors, even when inspecting detached or semi-detached structures. Again such choices are largely a matter of personal preference but whichever method is adopted it is usually best to follow the principle of starting at the top and working down. Thus the following sequence of inspection is recommended:

- Chimney stacks, flashings, cement fillets;

- Roofs, pitched and flat; main slopes, abutments, ridges, hips, verges, ventilation;

- Rainwater goods, gutters, downpipes, gulley or shoe;

- External walls, pointing, movement joints, damp-proof course, sub-floor ventilation;

- External joinery, fascias, soffits, windows, doors;

- Drainage, foul, above ground, below ground, surface water;

- Site, boundaries;

What to actually record during the inspection is not considered in detail in this paper. However there is now available comprehensive advice on this aspect 
of the inspection. SAVA (2000) have published detailed advice on precisely what to inspect when undertaking the intermediate type of survey (such as a Homebuyers Survey) and are shortly to publish a similar document for building surveys. It is to these documents that a court of law will refer in future should there be any suspicion of professional negligence by the surveyor. If the building being surveyed is large it is likely that the inspection of the exterior will have taken at least one or two hours. Once this is complete it is time to retreat to the interior where the higher temperature and a welcoming cup of coffee will be much appreciated, particularly during the winter months!

\section{Inspecting the interior}

The dangers of believing any information volunteered by the vendor are fairly obvious but there will no doubt be some matters that the surveyor wishes to clarify over a reviving beverage (of course an unoccupied and unheated building can be colder than the exterior and in such situations the surveyor will have come prepared with a thermos flask). However once the essential information has been requested of the occupier it is time to gain one's freedom once again and a useful ploy to achieve this is to commence the inspection of the interior in the roof-space. There are not too many vendors who will follow the surveyor into the furthest corners of the roof-space although unfortunately there will always be one or two, including in the writer's experience a very sprightly spinster in her seventies who would not let the surveyor out of her sight! There are however other, perhaps more compelling, reasons for starting in the roof-space. The first of these is that it continues the logical sequence of starting at the top and working down. Another is that it is possible to discover more about the quality of construction in the roof-space, where the builder would have made no attempt to disguise any short-comings, than anywhere else in a building. It is very often possible to date a building more precisely from within the roof-space. Even if the builder erected no plaque on the elevations to date the building, his tradesmen often left evidence in the form of an engraving in a roof-timber or cement rendering to a chimney breast (or even on some rare occasions a discarded newspaper read during their lunch-break). Finally a relatively high number of defects or 
matters requiring improvement are often identified in the roof-space. This is an area of their dwelling into which many owners or occupiers never venture and they are very often not aware of some of the defects revealed by a survey.

The essential matters which need to be investigated during a roof-space inspection are:

- Structural integrity of the frame;

- Evidence of fungal decay and insect infestation to timber members;

- Condition of the underside of roof coverings, or where felted or boarded, the felt or boarding;

- Condition of gable and party walls where applicable;

- Condition of chimney breasts and flues, including support provided where where removed at lower levels;

- Type and condition of ceilings;

- Presence of, extent of and condition of insulation;

- Condition of water tanks and plumbing;

- Type, age and condition of electrical wiring;

- Evidence of rodent, bird, bat and wasp infestation;

- Adequate ventilation.

Once the roof-space has been inspected each room (including circulation areas such as landings and staircases) should be inspected in detail. Again a logical sequence should be followed, such as inspecting in turn:

- Ceiling;

- Each wall (usually four);

- Window(s);

- $\operatorname{Door}(\mathrm{s})$;

- Radiator/heater/fireplace;

- Electrical fittings;

- Floor. 
Again it will be seen that the philosophy of working downwards from the top has been followed in each room and it is likely that the upper floors would be inspected before the ground floor (and basement if there is one). The surveyor will already be located at upper floor level after inspecting the roofspace and with any luck the owner or occupier will not be encountered again until the ground floor is reached.

\section{What should be recorded?}

Since the surveyor will need to convert his notes into the report it is important that the notes taken reflect what will be required in the report. For each element of construction it is necessary to record the following :

1. design and construction;

2. condition;

3. cause of any defects (or recommend further investigation);

4. remedial work required.

Thus two examples of the notes recorded during the inspection of elements of a semi-detached house are:

Roof

Double pitched with ridge running parallel to road and with hipped end at west side. Slopes covered with plain clay tiles with bonnet hip tiles and half round ridge tiles. Slopes even and coverings generally in sat isfactory condition. Two tiles to front slope and one each to side and rear slopes have slipped and require re-fixing. Ridge and hip tiles well bedded and pointed.

Bedroom 3 (North-east)

Ceiting

Papered finish. 
Paper loose at joins and evidence of cracking and bowing in ceiting.

Paper applied over whitewash and old lath and plaster ceiting has lost key.

Take down existing ceiling and replace with plasterboard and artex.

Obviously each surveyor will develop his own style of note-taking and may well abbreviate frequently used terms but provided that each of the four points are considered in the same order for each element inspected, error free report writing should follow.

\section{How should the information be recorded?}

There are a variety of methods of recording information on site and each surveyor will develop a preference for the method they employ. Each method is considered below:

- Taking notes by long-hand. This is obviously the most time consuming method but there should be a clear record of the inspection to rely upon at a later date, should that be necessary.

- Dictating notes into a portable tape-recorder for transcription back in the office. Provided there are no recording problems this is less time consuming on site (most people can talk seven times faster than they can write). However there is the delay while the notes are typed up and before the report can be commenced. There is also the disadvantage of having to dictate out of hearing of the owner or occupier.

- Both of the above methods can be supplemented by the use of site prepared sketches and many surveyors prefer to make their notes of each elevation on a sketch of that elevation. This approach has been strongly advocated by one leading authority (Hollis, 1995).

- Notes can be written on a pre-printed form or checklist. This method saves time in that the surveyor does not need to write most of the 
headings but it can be rather cumbersome. However the checklist approach is probably the best method for inexperienced surveyors.

- Dictating the report directly on site either for word-processing by a secretary or for use directly into speech recognition software - many practices have adopted the latter approach recently. There is no doubt that this is the quickest method and that adopted by many experienced surveyors who do not like to return to the office until after the report is substantially dictated. However in the case of Watts v Morrow (1991) the Judge considered that this method did not provide the surveyor the opportunity for reflective thought, which is most important when considering the property as a whole. The absence of any site notes leads the surveyor open to a claim of negligence when adopting this method. The writer suspects that those adopting this approach feel that commercial pressures outweigh the risks of being sued for negligence. No doubt a Judge would look more favourably upon a surveyor adopting this approach if there were some sketches with at least a minimum of annotation to record the inspection.

- Entering data directly into a hand held computer. This method is only suitable for stock condition surveys and not when any large volumes of text need to be included.

\section{Summary}

When carrying out domestic condition surveys an initial mechanistic task such as sketching the site and roof plans is recommended in order for the surveyor to achieve focus, familiarity and freedom to inspect alone. The writer recommends that the inspection commence with the exterior, followed by the interior, and that in general a top down approach be adopted. Note taking for each element should record design and construction, condition, cause of defects and then finally any remedial work required. Whichever method of note taking is used, the most important principle to observe is that there should be a comprehensive record of the inspection, to which to refer, if necessary, at a later date. 
What to inspect is not considered in detail here but such detailed information is contained in SAVA (2000) and this guidance is shortly to be extended. What has been presented in this paper is a procedural framework which will hopefully prevent the surveyor from missing vital information during the undertaking of the inspection.

\section{References}

Melville, I., Gordon, I., and Murrells, P., 1992, Structural Surveys of Dwelling Houses, Estates Gazette, London.

Hollis, M., 2000, Surveying Buildings, RICS Books, Coventry.

Hollis, M., 1995, Property Services - Part 2: The Exterior, The Chartered Surveyors' Education Channel Video.

SAVA, 2000, Benchmark Standards for the Homebuyer Survey and

Valuation, Surveyors and Valuers Accreditation, Woking Surrey.

Watts v Morrow (1991) 4 All ER 937, CA. 